\title{
PERCEPÇÃO DA LEGISLAÇÃO AMBIENTAL, GESTÃO E DESTINAÇÃO FINAL DOS RCD - RESÍDUOS DA CONSTRUÇÃO E DEMOLIÇÃO: UM ESTUDO DE CASO EM PARNAMIRIM/RN/BRASIL
}

\author{
A. L. DOS SANTOS; C. H. C. PINTO ${ }^{*}$ e A. C. M. M. CATUNDA \\ Universidade Federal do Rio Grande do Norte \\ carloscatunda@uern.br*
}

Artigo submetido em agosto/2013 e aceito em abril/2015

DOI: $10.15628 /$ holos.2015.1528

\section{RESUMO}

Sabe-se que a indústria da construção civil produz impactos negativos ao meio ambiente em toda sua cadeia produtiva, sendo que, um dos maiores poluidores desta indústria são os RCD - Resíduos da Construção e Demolição. O presente trabalho tem por finalidade principal analisar a percepção que os construtores associados ao SINDUSCON/RN, atuantes no município de Parnamirim/RN, tem à respeito da legislação ambiental específica vigente, bem como, o modelo de gestão adotado e a destinação final de tais resíduos. Este trabalho é um Estudo de Caso, cuja metodologia de pesquisa adotada é do tipo descritiva, de natureza aplicada e de abordagem quantitativa. Quatorze empresas aceitaram participar da pesquisa, que foi realizada através da aplicação de um questionário com perguntas fechadas e abertas a cada um dos gerentes das quatorze empresas no período de fevereiro a março de 2009. A pesquisa demonstra que uma parte considerável das empresas tem preocupação em atender às exigências da Legislação Ambiental vigente específica. No que se refere à questão da gestão ambiental, faz-se necessário que o Poder Público, conjuntamente com as organizações especializadas, possa oferecer programas específicos na área de gestão ambiental.

PALAVRAS-CHAVE: Resíduos da Construção e Demolição, Gestão Ambiental, Impactos Ambientais, Destinação Final de Resíduos.

\section{PERCEPTION OF ENVIRONMENTAL LAW, MANAGEMENT AND USE OF FINAL RCD - CONSTRUCTION AND DEMOLITION WASTES: A CASE STUDY IN PARNAMIRIM/RN/BRAZIL}

\begin{abstract}
It is known that the construction industry has negative impacts on the environment throughout its production chain, and one of the biggest polluters of this industry are the RCD - Waste from construction and demolition. The present work has the main purpose to analyze the perception that the builders associated with SINDUSCON/RN, working in the municipality of Parnamirim/RN, has to respect the existing specific environmental legislation, as well as the management model adopted and the disposal of such residues. This paper is a case study, the research methodology used is descriptive, the applied nature and a quantitative
\end{abstract}

approach. Fourteen companies agreed to participate in the survey, which was conducted through a questionnaire with closed and open questions to each of the fourteen companies managers from February to March 2009. The survey shows that a considerable proportion of businesses have concern meet the requirements of specific current environmental legislation. With regard to the issue of environmental management, it is necessary that the Government, together with specialized agencies, can offer specific programs in the area of environmental management.

KEYWORDS: Construction Waste and Demolition, Environmental Management, Environmental Impacts, Disposal of Waste. 


\section{INTRODUÇÃO}

Cada vez mais o mundo de um modo geral tem despertado para a problemática das questões ambientais. Governos, Organizações Governamentais e Não-Governamentais, a sociedade civil, etc., estão preocupadas com os impactos negativos que nosso Planeta tem sofrido, que já trazem enormes prejuízos para esta geração, mas, que, se não forem alvos de políticas que busquem solucionar ou minimizar tais impactos, redundarão em prejuízos incalculáveis e irreversíveis para as gerações futuras.

Entre os impactos negativos ao meio ambiente, estão aqueles que são gerados pelos Resíduos da Construção e Demolição (RCD), também conhecidos como Resíduos da Construção Civil, um dos maiores poluidores da sociedade. No Brasil, a perda total de materiais para construção empresarial (construção residencial em edifícios) varia entre 20 a 30\%; sendo um índice considerado elevado se comparado com padrões do Primeiro Mundo (SCHNEIDER, 2003 apud PINTO, 2003).

Tais resíduos quando não tratados e depositados de forma regular, correta e equilibradamente, podem trazer conseqüências profundas para todo o meio ambiente. Os principais impactos sanitários e ambientais relacionados aos RCD talvez sejam aqueles associados às deposições irregulares, uma "conjunção de efeitos deteriorantes do ambiente local: comprometimento da paisagem, do tráfego de pedestres e de veículos e da drenagem urbana, atração de resíduos não inertes, multiplicação de vetores de doenças e outros efeitos" (PINTO, 2001).

Tais fatores colocados acima ao destacarem tanto o aspecto da perda de materiais na cadeia produtiva da indústria da construção civil, assim como os aspectos relacionados à deposição irregular e desequilibrada dos RCD, levam-nos à reflexão de que é extremamente necessária a implementação de Políticas Públicas que venham minimizar os impactos ambientais negativos gerados no meio-ambiente.

Observa-se que, apesar da implementação da Resolução $\mathrm{N}^{\circ} 307 / 02$, de 05 de julho de 2002, do Conselho Nacional de Meio Ambiente (CONAMA), que dispõe sobre a gestão dos Resíduos da Construção Civil, a grande maioria das prefeituras dos municípios brasileiros, continuam enfrentando sérios problemas no que se refere à gestão dos RCD, sendo extremamente necessária a implementação de ações públicas que visem minorar tal problemática.

Vê-se que a despeito de política de coleta de RCD por parte do órgão competente, existe em todo município uma quantidade considerável de deposições a céu aberto, os conhecidos "bota-fora", principalmente advindas das pequenas demolições e reformas domiciliares, sendo bastante difícil à fiscalização por parte dos órgãos que visem minimizar o desperdício de materiais na cadeia produtiva da construção civil.

A urbanização é um fenômeno que vem se destacando no Brasil há muitos anos, onde tem se observado uma grande permuta dos domicílios rurais para domicílios urbanos.

Obviamente, o município de Parnamirim não foge ao que tem acontecido ao resto do mundo e do Brasil. Sua população urbana tem crescido consideravelmente nestes últimos anos. A 
população que em 2000 era de 124.690 habitantes, saltou para 143.598 em 2003, para 172.751 em 2007 e para 202.413 em 2010 (IBGE, 2010). Intrinsecamente relacionado ao crescimento urbano, está à indústria da construção civil, pois para acomodar mais e mais pessoas dentro da urbis, faz-se necessária à construção de novas residências, ou pelo menos a reforma daquelas já existentes.

Observa-se que a estabilidade econômica em nosso país tem levado a um aquecimento na indústria da construção civil, tanto no que se refere a grandes e complexas obras, como àquelas de pequeno porte. O Estado do Rio Grande do Norte tem demonstrado sensível crescimento na área da construção civil como demonstra a tabela 1 a seguir, que se refere ao acompanhamento de lançamentos imobiliários.

Tabela 1 - Acompanhamento de lançamentos imobiliários.

\begin{tabular}{c|c|c|c|c}
\hline Ano & $\begin{array}{c}\text { Unidades } \\
\text { Previstas }\end{array}$ & $\begin{array}{c}\text { Valor Geral de Vendas } \\
\text { - Previsão } \\
\text { (Em milhões) }\end{array}$ & $\begin{array}{c}\text { Unidades } \\
\text { Lançadas }\end{array}$ & $\begin{array}{c}\text { Valor Geral de Vendas } \\
\text { Realizadas (Em milhões) }\end{array}$ \\
\hline 2004 & - & 100 & 1.700 & 150 \\
\hline 2005 & 2.500 & 330 & 1.600 & 190 \\
\hline 2006 & 2.800 & 345 & 1.536 & 198 \\
\hline 2007 & 7.816 & 1,15 bilhão & 2.232 & 320 \\
\hline 2008 (até outubro) & 7.000 & 1,0 bilhão & 3.185 & 682 \\
\hline \multicolumn{7}{r}{}
\end{tabular}

A indústria da construção civil no município de Parnamirim tem se mostrado bastante aquecida. Em diversos bairros e localidades, a população tem que aprender a conviver com os canteiros de obras. Como exemplo, apresentamos o bairro de Nova Parnamirim, onde na localidade conhecida como Residencial das Nações, foram construídos cerca de 10 blocos de edifícios, cada um com dezesseis apartamentos e cerca de 1.200 novas casas. E até março de 2010 foram entregues 4.624 unidades habitacionais (COOPHAB, 2013). Some-se a isto as grandes obras públicas que estão sendo implementadas em todo o município, principalmente na área de saneamento e tratamento de águas pluviais. Alie-se também a isto, as pequenas reformas que estão sendo realizadas nos mais diversos domicílios, tanto comerciais como residencial, e teremos uma grande quantidade de RCD que precisam ser bem geridas, senão correm o risco de trazerem enormes prejuízos para o meio-ambiente.

Diante do acima exposto, a presente pesquisa teve como objetivo diagnosticar a percepção das Construtoras atuantes em Parnamirim/RN e associadas ao SINDUSCON/RN (Sindicato da Indústria da Construção Civil no Rio Grande do Norte) frente à Legislação Ambiental, assim como, analisar a gestão e a destinação final dos RCD produzidos pelas mesmas.

\section{A INDÚSTRIA DA CONSTRUÇÃO CIVIL E O MEIO AMBIENTE}

A importância econômica da indústria da construção civil é notória a todos, sendo a mesma importante para vários segmentos da sociedade. A cadeia produtiva do segmento, dividida em diversos sub-setores, tais como: material de construção, bens de capital para construção, edificações, construção pesada e serviços diversos, que incluem: atividades imobiliárias, serviços técnicos de construção e atividades de manutenção de imóveis; é 
extremamente relevante para economia do país, representando cerca de $15 \%$ do Produto Interno Bruto - PIB nacional, além de ser a maior geradora de empregos diretos e indiretos do país (SINDUSCON-SP, 2005).

Além disso, a indústria da construção civil é responsável por $40 \%$ da formação bruta de capital e absorção de grande massa de trabalho, além de ser uma das maiores consumidoras de matérias primas naturais (COSTA, 2005). Estima-se que a construção civil consome em torno de 20 e 50\% do total dos recursos naturais consumidos pela sociedade (COSTA, 2003 apud SJOSTROM, 1996).

O grande potencial econômico e produtivo da indústria da construção civil reflete decisivamente na geração de resíduos sólidos urbanos. Estima-se que a indústria da construção produz cerca de $50 \%$ do peso total dos resíduos sólidos urbanos produzidos diariamente em grandes cidades brasileiras, com mais de 500 mil habitantes (CONAMA, 2002). Nas cidades brasileiras de médio e grande porte, segundo Pinto (1999), os resíduos provenientes de construções e demolições representam de 40 a $70 \%$ da massa total dos resíduos sólidos urbanos.

Por conseguinte, a indústria da construção se depara hoje com uma grande problemática: o que fazer com todos os resíduos produzidos nos canteiros de obras? Pois os mesmos se depositados irregularmente podem trazer inúmeros malefícios ao meio ambiente e à saúde humana. Obviamente que este não é um problema enfrentado apenas pelos construtores, mas, também pelos gestores governamentais e pela sociedade como um todo, que pode ser a maior vítima em caso de poluição gerada pelos resíduos da construção.

Administrar a grande quantidade de resíduos gerados visando a sua diminuição e a sua correta destinação tem sido o grande desafio para as cidades, principalmente depois de ser divulgada a Resolução N 307/02 do Conselho Nacional do Meio Ambiente (CONAMA), que exige dos geradores e dos gestores propostas de gestão dos resíduos.

Nesse sentido, a indústria da construção tem que repensar e rever urgentemente suas atividades, pois, como a atividade econômica representa um elemento principal do ambiente urbano, tanto pelo uso e ocupação do solo como pelo fornecimento de infra-estrutura (COSTA, 2003). É indispensável pensar a administração do ambiente urbano pela ótica do desenvolvimento sustentável.

\subsection{OS RCD E A LEGISLAÇÃO AMBIENTAL VIGENTE}

Em 02 de Janeiro de 2003 entrou em vigor a Resolução do CONAMA N 307 de 05 de julho de 2002 que trata sobre a gestão dos resíduos da construção civil, visando criar instrumentos para superação dos problemas dos RCD, definindo responsabilidades e deveres, abrindo caminho para o preparo de normas técnicas, tanto para o correto manejo dos resíduos, como para o uso pós-reciclagem (COSTA, 2005).

Tal Resolução impõe aos geradores a obrigatoriedade da redução, reutilização e reciclagem dos materiais. Contudo, diante das características dos geradores, cabe aos municípios e Distrito Federal, a responsabilidade de desenvolverem e implementarem Planos Integrados de Gerenciamento que possibilitem a expressão das responsabilidades dos geradores (COSTA, 2005). 
Um aspecto de extrema importância na Resolução do CONAMA N³07/02 trata-se da solução encontrada para a abolição dos conhecidos "bota-foras" de entulhos da construção. Se não há ainda viabilidade em exigir-se a reciclagem dos resíduos captados da construção urbana, não se poderia aceitar a continuidade desta prática altamente poluente (COSTA, 2005). Não poderemos ter no curto prazo, índices elevados de retorno de RCD ao ciclo produtivo, mas podemos adotar práticas que respeitem esses materiais como recursos naturais não-renováveis (PINTO, 2004).

\subsection{GERAÇÃO E DESTINAÇÃO DOS RCD}

Segundo John (2000) a indústria da construção civil gera resíduos na fase de produção de materiais e componentes, na atividade de canteiro, durante a manutenção, modernização e, finalmente, na demolição. Em cada parte, a quantidade de resíduos gerados depende da intensidade da atividade de construção, da tecnologia empregada e das taxas de desperdício e manutenção.

Na prática, todas as atividades desenvolvidas no setor da construção civil têm potencial para gerar resíduos. Na produção, o grande volume de perdas de material é o principal responsável pela geração de RCD. Nas obras de demolição propriamente dita, a quantidade de resíduo gerado, não depende dos processos empregados ou da qualidade do setor, pois se trata do produto do processo, e essa origem sempre existirá (ZORDAN, 1997).

A produção de RCD no Brasil ainda é bastante elevada quando comparada com os países desenvolvidos. A mesma varia entre $230 \mathrm{Kg} / \mathrm{hab}$-ano até $660 \mathrm{Kg} / \mathrm{hab}$-ano (PINTO, 1999). Monteiro et al. (2001) informa que nos países desenvolvidos a média de resíduos provenientes de novas edificações encontra-se abaixo de $100 \mathrm{~kg} / \mathrm{m}^{2}$, enquanto que no Brasil este índice gira em torno de $300 \mathrm{~kg} / \mathrm{m}^{2}$ edificado.

Um dos principais fatores de geração de RCD é o elevado índice de perdas no processo produtivo da indústria da construção. Para muitos pesquisadores, as perdas são as principais causas da geração de RCD. Apesar do fato de que nem toda perda dentro da obra representar efetivamente geração de resíduo, cerca de $50 \%$ do material desperdiçado torna-se entulho (PINTO, 1989).

Souza et al. (1999) classifica as perdas nas construções da seguinte forma: perdas evitáveis decorrentes de desperdício; perdas inerentes ao processo construtivo; perdas de produtividade referentes ao uso indevido do tempo de trabalho; perdas inevitáveis decorrentes de fatores climáticos e perdas agregadas, resultantes de materiais aplicados para sanar incorreções de projetos ou incompatibilidade entre os mesmos.

Outro grande gerador de RCD são as reformas e as demolições. Em se tratando de reformas, o desconhecimento de técnicas apropriadas e a falta de informação quanto à reutilização e reciclagem de materiais tornam-se os principais inimigos e geradores de desperdício de materiais, que facilmente teriam grande potencial de aproveitamento e conseqüentemente, auxiliaria na redução da geração de resíduos sólidos (BRITO FILHO, 1999).

A destinação final dos RCD é outro grande problema enfrentado pelo segmento da construção, tanto no que se refere às grandes obras, quanto às de pequeno porte. $O$ que se observa na prática, é que apesar de existir legislação que se aplica a tal questão, a deposição 
irregular dos RCD continua existindo em praticamente todas as cidades do país, principalmente aqueles atrelados às obras de médio e pequeno porte.

Como colocado, a problemática é mais intensa em obras de médio e pequeno porte, notadamente àquelas relacionadas a reformas e demolições, acima de tudo por falta de uma gestão eficiente dos órgãos fiscalizadores, bem como pela inexistência de uma cultura e consciência ambiental por parte dos construtores e população em geral. Como não existem soluções práticas para a captação dos RCD deste tipo de construção, inevitavelmente, seus geradores ou pequenos coletores, buscarão áreas livres nas proximidades para efetuar a deposição dos RCD. Havendo ou não a aceitação da vizinhança imediata, essas áreas acabam por se firmar como sorvedouros dos RCD, num "pacto" local, atraindo, por fim, todo e qualquer tipo de resíduo para o qual não se tenha solução de captação rotineira (PINTO, 1999).

\subsection{GESTÃO DOS RCD}

Os resíduos sólidos, em geral, constituem um dos principais causadores da degradação ambiental, tanto pelo volume gerado como por seu tratamento e sua destinação inadequados. Sua gestão representa um dos principais problemas a serem resolvidos por organismos do governo e prefeituras municipais (COSTA, 2003).

É importante frisar que nenhuma sociedade poderá atingir o desenvolvimento sustentável sem que a construção civil, que lhe dá suporte passe por profundas transformações (FILHO, 2005 apud POLILLO, 2001).

No Brasil, a preocupação com os RCD é recente, sendo que, na Europa e nos EUA a preocupação com os RCD começou logo após a Segunda Guerra Mundial. Contudo, vários passos têm sido dados com vistas a minorar a problemática advinda com a produção dos RCD, e, hoje, no Brasil, a gestão da indústria da construção civil é uma imposição legal, devendo ser implementada e fiscalizada (AGOPYAN e JOHN, 2000).

\section{MATERIAL E MÉTODO DE PESQUISA}

Gil (1999) define pesquisa científica como o processo formal e sistemático de desenvolvimento do método científico, cujo objetivo principal é descobrir respostas para problemas mediante o emprego de procedimentos científicos.

Vergara (1998) diz que uma pesquisa pode ser classificada quantos aos fins e quantos aos meios. Por sua vez quanto aos fins, uma pesquisa pode ser classificada como descritiva; e, quanto aos meios, ela pode ser classificada como bibliográfica e de campo. Já a pesquisa de campo é classificada como quantitativa quando é procedida através da aplicação de questionários com estrutura pré-definida, onde se objetiva analisar estatisticamente os dados levantados.

Este trabalho é um Estudo de Caso, cuja metodologia de pesquisa adotada é do tipo descritiva, de natureza aplicada e de abordagem quantitativa, tendo sido iniciado a partir da revisão bibliográfica referente ao tema, tais como: artigos científicos, trabalhos acadêmicos diversos (teses e dissertações), normas, legislações e outras fontes.

No presente trabalho foram analisadas e estudadas as seguintes variáveis:

- Análise das empresas no que se refere à Legislação Ambiental específica vigente; 
- Análise das empresas quanto a Gestão Ambiental e dos RCD; e

- Análise da Destinação Final dos RCD.

Para coleta dos dados, foi realizada pesquisa junto à Secretaria de Meio Ambiente e Urbanismo (SEMURB) e Secretaria de Obras Públicas (SEMOP) do município de Parnamirim-RN, com vistas a se levantar a quantidade e nomes das construtoras atuantes em todo o município. Em seguida, foi realizada pesquisa junto ao SINDUSCON/RN (Sindicato da Indústria da Construção Civil no Rio Grande do Norte) com o objetivo de se identificar às empresas que são associadas à entidade, sendo identificadas dezesseis empresas. Destas, quatorze empresas aceitaram participar da pesquisa, que foi realizada através da aplicação de um questionário com perguntas fechadas e abertas a cada um dos gerentes das quatorze empresas no período de fevereiro a março de 2009.

Realizada a pesquisa, os resultados foram agrupados, quantificados e analisados com base em estatística básica, com vistas à elaboração das figuras e tabelas, objetivando-se a facilitação das interpretações e discussões.

\section{ANÁLISE DE DADOS E RESULTADOS}

A seguir apresentamos a análise de dados e resultados alcançados das análises das empressas pesquisadas, com relação a legislação ambiental, gestão ambiental e dos RCD e a destinação final dos RCD.

\subsection{Análise das empresas no que se refere à legislação ambiental específica vigente}

A figura 1 mostra o nível de conhecimento dos entrevistados sobre a legislação ambiental referente aos RCD - Resíduos da Construção e Demolição.

Nota-se na figura 1 que $21,43 \%$ dos entrevistados afirmaram que tem pouco conhecimento sobre a legislação ambiental referente aos RCD, 35,71\% afirmaram que tem conhecimento moderado sobre a legislação ambiental referente aos RCD, 28,57\% dos entrevistados afirmaram que tem grande conhecimento sobre a legislação ambiental referente aos RCD e apenas $14,29 \%$ declarou que tem conhecimento muito grande sobre a legislação ambiental referentes aos RCD.

Observa-se um percentual elevado de entrevistados que afirmaram pouco conhecimento e conhecimento moderado especificamente à legislação ambiental específica à área de atuação. Se somados os que afirmaram ter pouco conhecimento com aqueles que disseram ter conhecimento moderado, tem-se quase $60 \%$ dos entrevistados, que representa um percentual significativo.

O conhecimento da legislação específica à gestão dos RCD é indispensável para as empresas que atuam no segmento da Construção Civil e para as empresas que atuam como Coletoras. A Resolução 307/02 do CONAMA traz os subsídios necessários para a correta gestão dos RCD por parte dos seus geradores.

Nota-se na figura 2 que 35,71\% dos entrevistados responsáveis pelas construtoras apresentaram preocupação moderada com relação ao cumprimento da legislação ambiental, 
$7,14 \%$ dos respondentes afirmaram ter grande preocupação e 57,14\% declaram ter preocupação muito grande com relação ao cumprimento da legislação ambiental.

Se somados os entrevistados que demonstram ter grande preocupação com aqueles que responderam ter uma preocupação muito grande, teremos $64 \%$ dos entrevistados; o que sugere uma contradição se comparada à questão anterior, ou seja, existe uma elevada preocupação em se cumprir à legislação, mas, a mesma não é conhecida como deveria, muito embora esteja disponível a todos.

Sabe-se que para o desenvolvimento de um modelo de gestão ambiental sustentável a relação com as leis ambientais são imprescindíveis. Numa grande maioria dos casos, os agentes poluidores do meio ambiente estão mudando sua postura de produção, e elaborando modelos de gerenciamento sustentáveis devido à força das leis ambientais, particularmente, de instrumentos legais que determinam diretrizes e aplicam sanções (ROCHA, 2006).

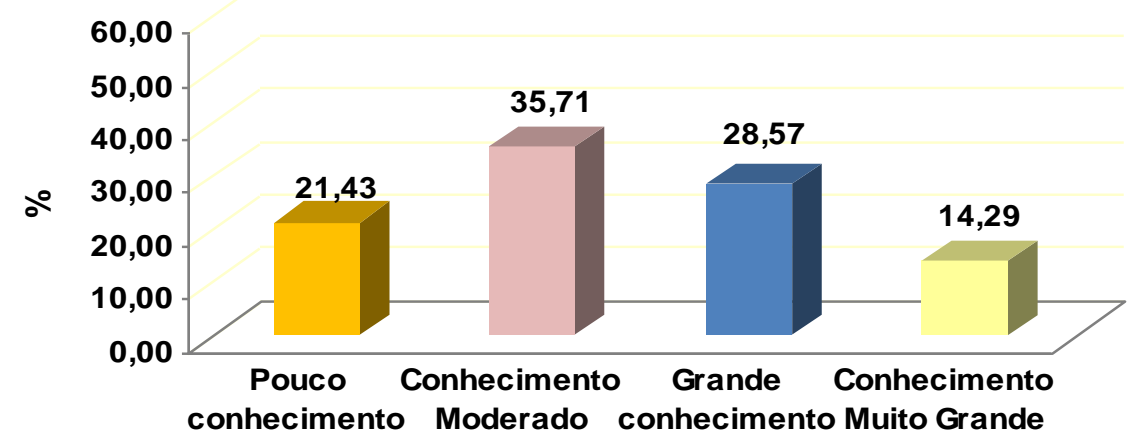

Figura 1 - Nível de conhecimento sobre a legislação ambiental referente aos RCD - Resíduos da Construção e Demolição. Fonte: Elaboração do autores, fevereiro/março 2009.

A figura 2 mostra o nível de preocupação das empresas pesquisadas em cumprir a legislação ambiental relacionada à área de atuação:

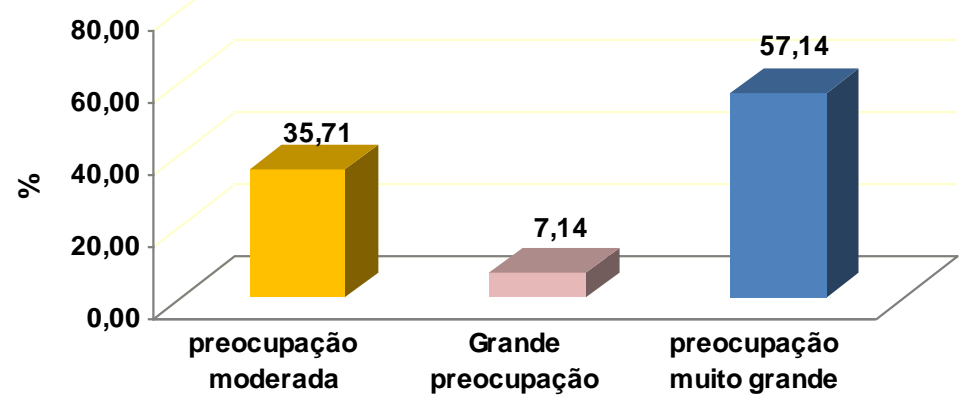

Figura 2 - Nível de preocupação das empresas em cumprir a legislação ambiental relacionada à área de atuação (construção civil). Fonte: Elaboração do autores, fevereiro/março 2009.

A figura 3 mostra em que nível a legislação ambiental tem prejudicado às atividades da empresa: 


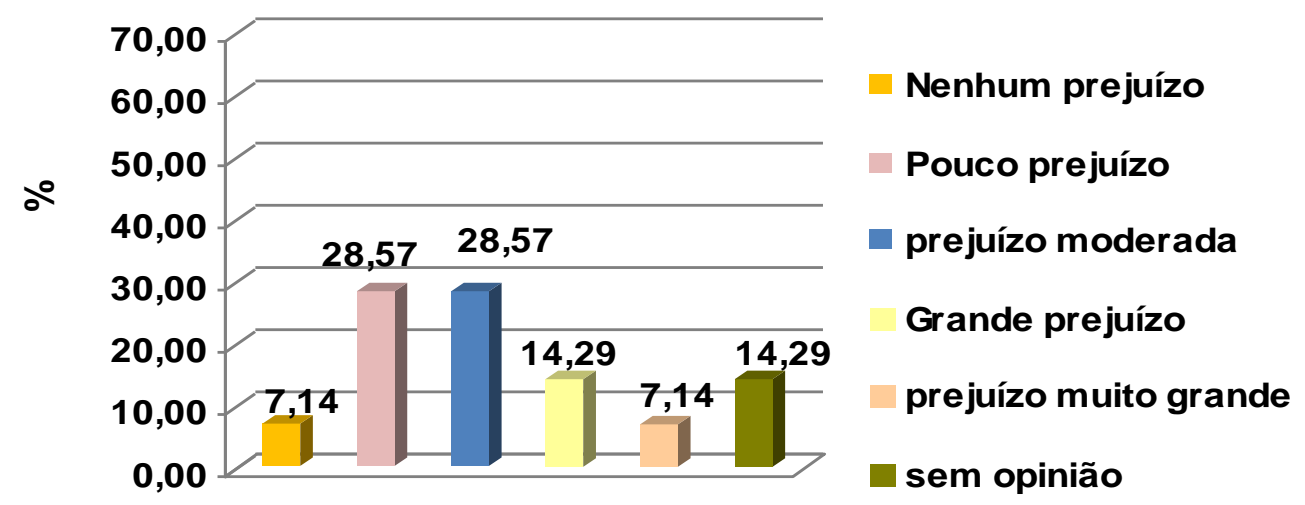

Figura 3 - Nível em que a legislação ambiental tem prejudicado às atividades da empresa. Fonte: Elaboração do autores, fevereiro/março 2009.

Nota-se na figura 3 que 7,14\% dos entrevistados responsáveis pelas construtoras afirmaram que a legislação ambiental não causou prejuízo as atividades, 28,57\% afirmaram que a legislação ambiental causou pouco prejuízo, 28,57\% declaram que a legislação ambiental causou prejuízo moderado, $14,29 \%$ dos entrevistados declararam que a legislação ambiental causou grande prejuízo, $7,14 \%$ afirmaram que a legislação ambiental causou prejuízo muito grande e $14,29 \%$ dos entrevistados não souberam opinar.

Neste quesito, observa-se que as empresas pesquisadas não demonstram grande insatisfação com à legislação ambiental vigente, onde $57,14 \%$ dos entrevistados disseram que a legislação ambiental tem causado pouco/moderado prejuízo às suas atividades. Talvez, isto devese ao fato da necessidade de uma fiscalização mais eficiente por parte dos Órgãos compententes.

\subsection{Análise das empresas quanto a Gestão Ambiental e dos RCD}

A figura 4 mostra se a empresa possui algum tipo de programa de gestão de resíduos.

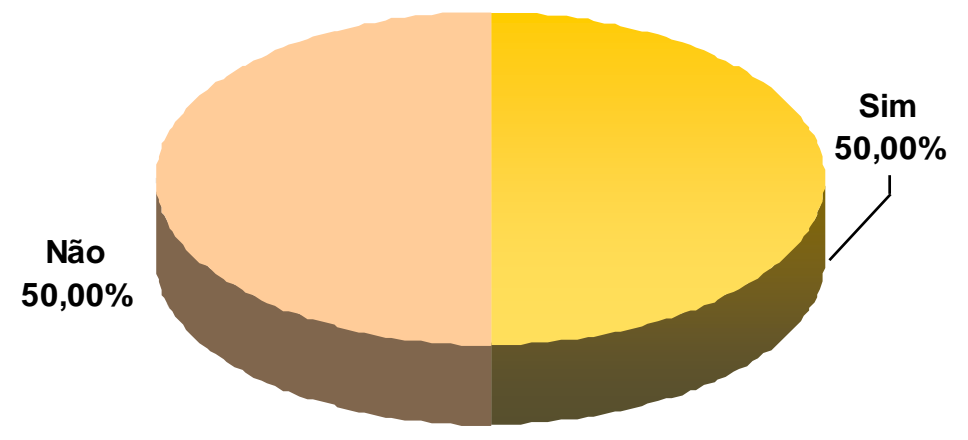

Figura 4 - Desenvolvimento de Programa de Gestão de Resíduos. Fonte: Elaboração do autores, fevereiro/março 2009.

Nota-se na figura 4 que 50,00\% das empresas possuem algum programa de gestão de resíduos e $50,00 \%$ das empresas não possuem programa de gestão de resíduos. Os $50,00 \%$ dos entrevistados que afirmaram ter algum programa de gestão de resíduos, trata-se praticamente do reaproveitamento dos RCD na própria obra. Isto foi observado através de questão aberta subsequente que perguntava como era o modelo da gestão dos resíduos. 
A questão de uma gestão sustentável para os RCD tem sido um grande desafio para a indústria da construção civil e dos administradores públicos, pois as cidades têm sentido o impacto causado pelos descartes ilegais e da presença dos RCD em ambientes urbanos. Conforme se observa na questão em discussão a maioria dos entrevistados não possuem um programa específico que contemple a gestão dos RCD.

O termo gestão pode ser definido como o uso prudente de um meio para alcançar um fim. Contudo, nem sempre o termo "gestão" vem sendo empregado de forma correta quando aplicado no caso dos resíduos provenientes das atividades relacionadas à construção civil, pois, geralmente os meios utilizados não são prudentes e os fins quase nunca são alcançados em sua plenitude (KARTAM et al, 2004 apud TAVARES, 2007).

Na maioria das cidades brasileiras, o modelo de gestão comumente adotado para os RCD é do tipo corretivo. Esse modelo se mostra ineficiente, caracterizado por não englobar atividades não preventivas, repetitivas e custosas, que não surtem os resultados adequados. Pode-se caracterizar a gestão corretiva dos RCD como uma prática sem sustentabilidade (EDUFBA, 2001 apud TAVARES, 2007).

Para Pinto (1999), é necessário romper com a cultura da gestão corretiva e implementar a gestão diferenciada. Esta deve ser vista como solução necessária e complementar à gestão tradicional, introduzindo preceitos modernos na gestão dos sólidos urbanos como a coleta seletiva e reciclagem de embalagens, a compostagem de resíduos orgânicos e podas vegetais, e o reaproveitamento dos resíduos volumosos, como por exemplo, os RCD.

A metodologia para a gestão diferenciada é um conjunto de ações de entes públicos e privados, visando à reorientação de sua prática, para que recursos naturais não renováveis sejam usados com racionalidade e o ambiente seja preservado da disposição aleatória de resíduos com elevado potencial de aproveitamento (PINTO, 1999). Entre as ações para uma gestão diferenciada no que se refere exclusivamente aos RCD, destaca-se resumidamente: captação máxima dos resíduos gerados por meio de centrais de Entulhos, para pequenos e grandes geradores; reciclagem dos resíduos captados em áreas pré-definidas para esta finalidade; alteração de procedimentos e culturas referentes à intensidade da geração, melhoria das práticas de coleta e disposição e promoção do uso dos produtos reciclados; facilitação da disposição dos RCD pela oferta mais abrangente possível de áreas públicas de pequeno e médio porte; e segregação na captação, objetivando-se diferenciar, organizar e remover adequadamente outros resíduos que transitam com os RCD.

Faz-se necessário que os principais atores envolvidos na questão da gestão dos RCD, notadamente as empresas atuantes na construção civil e os gestores públicos, passem urgentemente a repensar o modelo e as práticas de gestão de RCD sustentável. O objetivo final é o desenvolvimento econômico e produtivo que traga o mínimo de impacto ambiental negativo à cidade, e, por conseguinte, aos seus habitantes.

A figura 5 mostra se a empresa desenvolve outro programa de gestão ambiental: 


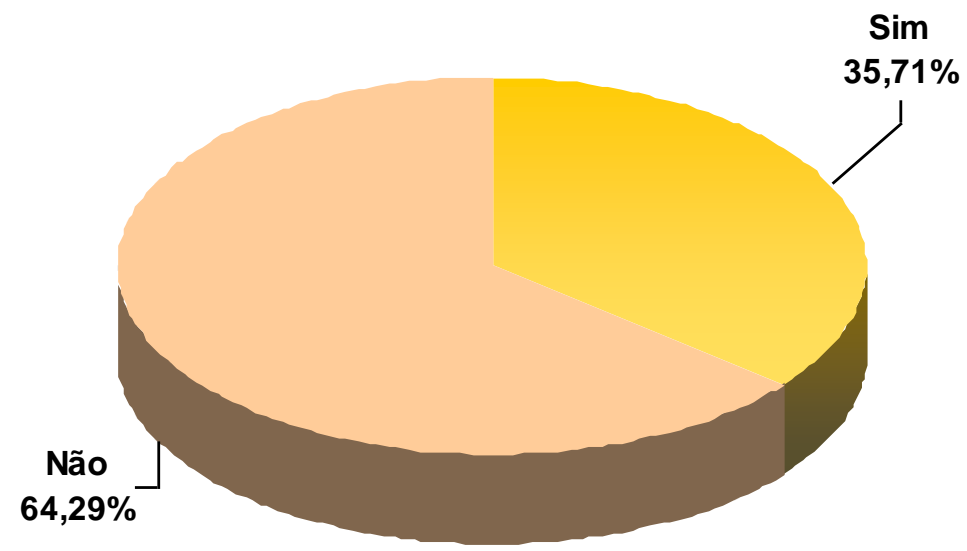

Figura 5 - Desenvolvimento de Outro Programa Ambiental. Fonte: Elaboração do autores, fevereiro/março 2009.

Observa-se na figura 5 que 64,29\% das construtoras não desenvolveram outro programa ambiental e apenas $35,71 \%$ das construtoras desenvolveram outro programa ambiental.

Percebe-se que as empresas pesquisadas necessitam de um maior envolvimento com a área de gestão ambiental, sendo relevante o despertamento para o conceito de Construção Limpa e Desenvolvimento Sustentável, pois a grande maioria não desenvolve nenhum outro programa na área ambiental, senão aqueles relacionados à sua área de atuação, que como vimos na questão anterior, resume-se praticamente a reutilização dos RCD na própria obra.

Para efetivação dos pressupostos do Desenvolvimento Sustentável, necessário se faz por parte dos atores envolvidos, notadamente aqueles ligados diretamente à produção e os gestores públicos, a adoção de políticas relacionadas à Gestão Ambiental.

Faz-se mister a implementação de um Sistema de Gestão Ambiental que venha nortear as ações de produção, desenvolvimento e organização das empresas e órgãos públicos com vistas a atenuar e minimizar os impactos ambientais oriundos do processo produtivo.

É extremamente relevante que a gestão ambiental seja abrangente e inclua desde os problemas econômicos e sociais até os da organização e os de seus colaboradores, passando pelos aspectos ligados ao setor industrial (DEGANI, 2003).

O sistema de gestão ambiental propõe a estrutura para que as empresas possam alcançar a melhoria contínua, na velocidade e amplitude por elas determinadas. Embora sejam esperadas melhorias no desempenho ambiental, entende-se que o sistema de gestão ambiental é apenas uma ferramenta auxiliar para a organização atingir, e sistematicamente controlar o nível de desempenho ambiental por ela mesma estabelecido.

A figura 6 apresenta o nível da interesse da empresa em participar de um Programa de Gestão Ambiental desenvolvido pelo Poder Público ou Organizações Especializadas: 


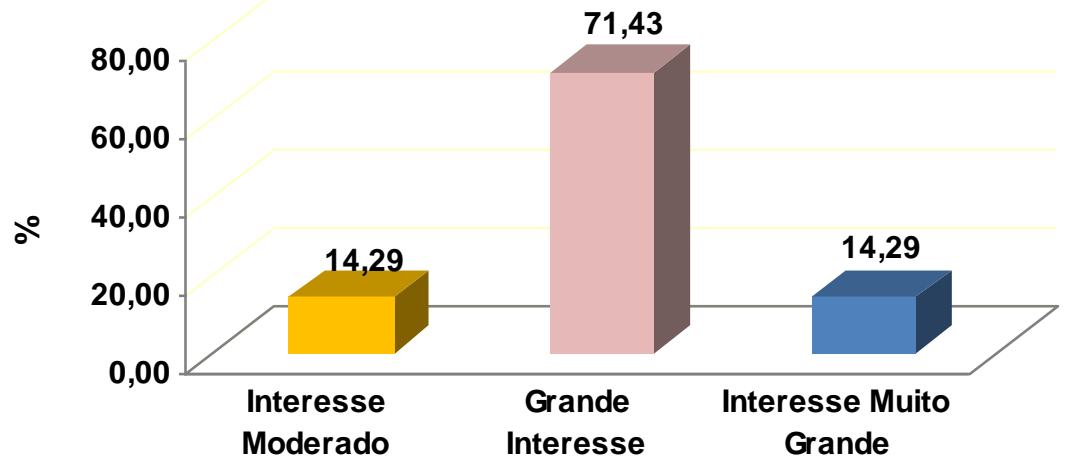

Figura 6 - Interesse da Participação em Programa de Gestão Ambiental desenvolvido pelo Poder Público e/ou Organizações Especializadas.

Fonte: Elaboração do autores, fevereiro/março 2009.

Observa-se na figura 6 que 14,29\% das empresas têm interesse moderado de participar de um programa de gestão ambiental desenvolvido pelo poder publico, $71,43 \%$ tem grande interesse e $14,29 \%$ tem interesse muito grande.

Este é um dado muito importante e relevante, pois se somados grande interesse/interesse muito grande, chega-se ao percentual de quase $86,00 \%$, ou seja, a maioria das empresas entrevistadas estaria disposta a participar de programas de gestão ambiental, como adoção de políticas relacionadas à gestão ambiental direcionadas especificamente com a questão de RCD nos canteiros de obras.

Esta é uma informação muito interessante para a implementação de Programas e Projetos na área de gestão ambiental para uma construção mais limpa e um Desenvolvimento Sustentável por parte dos Órgãos públicos, assim como por Organizações Não-Governamentais que atuam com ações que envolvem questões do meio ambiente.

Percebe-se que nas cidades onde o modelo de gestão dos RCD tem demonstrado resultados positivos (prática de gestão diferenciada), as iniciativas para implementação e incrementação de Projetos e Ações, na maioria dos casos, partiram das municipalidades, que diante de uma problemática tão grave, se viram obrigadas a discutir e colocar em práticas modelos de gerenciamento sustentáveis.

\subsection{Análise da Destinação Final dos RCD}

A destinação final dos RCD tem sido um dos maiores problemas enfrentados pelos gestores públicos, haja vista que, apesar da Legislação vigente, várias empresas e os pequenos construtores e reformadores, continuam depositando as sobras e os rejeitos das construções e reformas em locais indevidos e inapropriados, conforme demonstrado nas figuras 7 e 8 : 


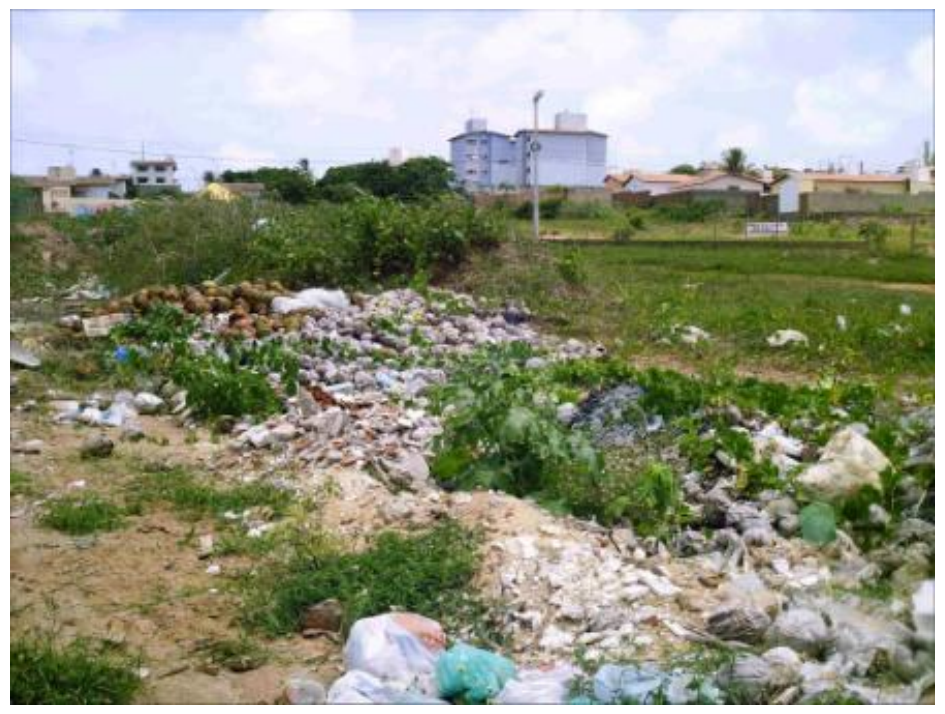

Figura 7 - Deposição irregular de RCD na RN 063 (Estrada de Pium - Nova Parnamirim - Parnamirim/RN). Fonte: Elaboração do autores (2009).

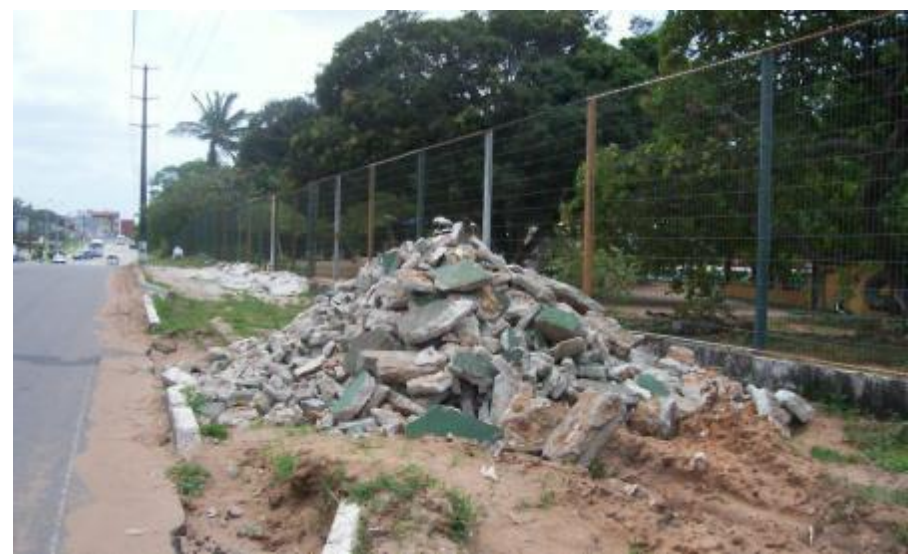

Figura 8 - Deposição irregular na Av. Maria Lacerda Montenegro, 1864 - Nova Parnamirim - Parnamirim/RN). Fonte: Elaboração do autores (2009).

A tabela 2 apresenta a destinação final dos RCD nas empresas pesquisadas:

Tabela 2 - Destinação Final dos RCD

\begin{tabular}{l|c|c}
\hline \multicolumn{1}{c|}{ Destinação } & Quantidade de Empresas & Média (\%) \\
\hline Terreno Baldio (Bota-Fora) & 03 & 20,0 \\
\hline Aterro da Prefeitura & 09 & 71,1 \\
\hline Destino Desconhecido & 05 & 32,4 \\
\hline Outros: Reaproveitamento & 08 & 58,8 \\
\hline \multicolumn{2}{|c}{ Fonte: Elaboração do autores (2009). }
\end{tabular}

Faz-se importante ressaltar, que nesta questão, os entrevistados podiam responder mais de uma opção.

Nota-se na tabela 2 que entre as empresas analisadas, 3 delas lançam algum RCD em terreno baldio, entre essas construtoras percebe-se que em média $20 \%$ dos RCD gerados são lançados em terreno baldio. Observa-se que 9 empresas lançam os RCD em aterros da prefeitura, em média $71,1 \%$ dos RCD tem esse destino, 5 construtoras não sabe o destino dos RCD, em 
média 32,4\%, e 8 empresas fazem reaproveitamento dos RCD, entre as empresas que fazem reaproveitamento, nota-se que em média $58,8 \%$ dos RCD são reaproveitados na própria obra.

Observa-se que a média de RCD lançados em terreno baldio (Bota-Fora) é um percentual considerável $(20,0 \%)$, sendo estes os principais instrumentos de impactos ambientais negativos ao meio ambiente. Além desse dado, nota-se que 32,4\% dos RCD tem destino desconhecido, o que pode ser um dado preocupante, pois, tais RCD podem estar sendo lançados em locais indevidos e inapropriados. Um dado importante, é que quase $60,0 \%$ dos entrevistados disseram reaproveitar o RCD na própria obra. Sendo portanto diferente do que foi respondido com relação a figura 4, onde os mesmos informam que 50,0\% dos entrevistados realizavam reaproveitamento. Sendo assim, existe pelo menos alguma informação desincontrada por parte dos entrevistados. Sendo assim, o modelo de gestão é bastante simples e ajuda a minorar a problemática da destinação final dos RCD.

Sabe-se que a deposição irregular dos RCD é um dos maiores problemas enfrentados pelas municipalidades, com um alto custo social e ambiental. A prática de deposição ilegal provoca a degradação da qualidade de vida urbana em aspectos como transporte, enchentes, poluição visual, proliferação de vetores de doenças, assoreamento e poluição de leitos de água, entre outros (TAVARES, 2007). A seguir, nas figuras 9 e 10, observa-se deposição irregular no contexto urbano do município de Parnamirim.

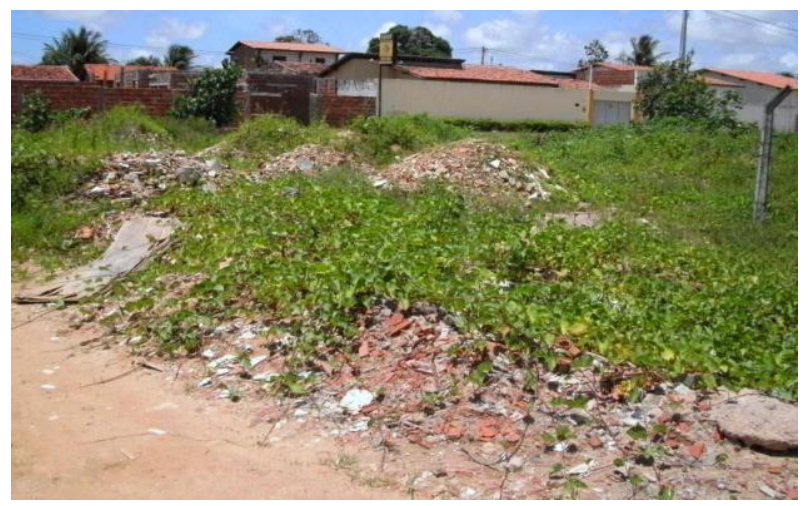

Figura 9 - Deposição irregular na Avenida Perimetral, Residencial Vida Nova II - Monte Castelo - Parnamirim-RN. Fonte: Elaboração do autores (2009).

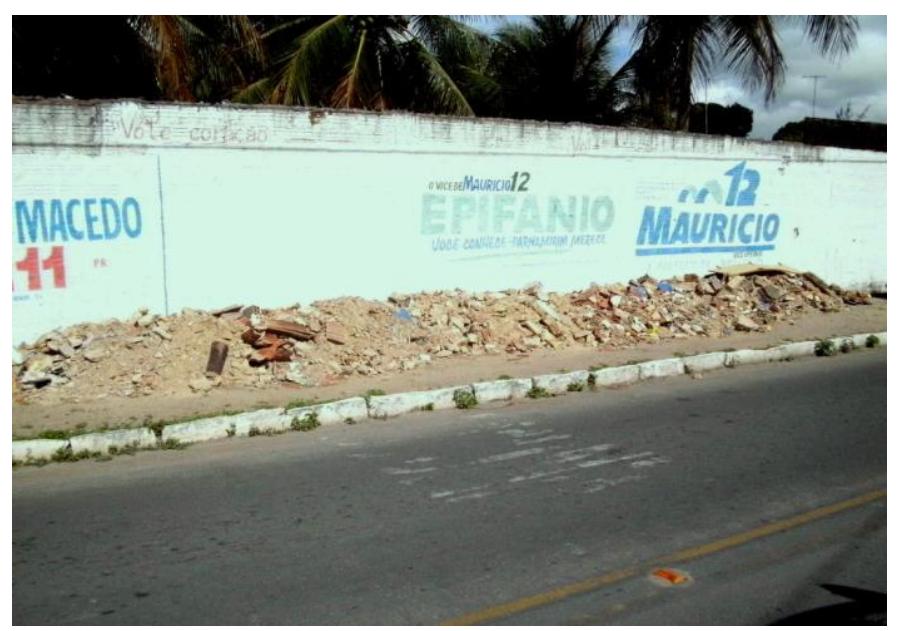

Figura 10 - Deposição irregular na Avenida Cajupiranga - Primavera - Parnamirim-RN. Fonte: Elaboração do autores (2009). 


\section{CONSIDERAÇÕES FINAIS}

Apesar da implementação da Resolução N³07/02, de 05 de julho de 2002, do Conselho Nacional de Meio-Ambiente (CONAMA), que dispõe sobre a gestão dos Resíduos da Construção Civil, a Prefeitura do Município de Parnamirim-RN, no nordeste brasileiro, continua enfrentando sérios problemas no que se refere à gestão dos RCD.

A pesquisa demonstra que uma parte considerável das empresas tem preocupação em atender às exigências da Legislação Ambiental vigente específica; contudo, existe a necessidade de um maior conhecimento da mesma. Neste caso, é importante que o Poder Público, através dos órgãos competentes, possa repassar informações referentes à Legislação Ambiental específica, e, ao mesmo tempo, exigir o seu devido cumprimento.

No que se refere à questão da gestão ambiental, faz-se necessário que o Poder Público, conjuntamente com as organizações especializadas, possa oferecer programas específicos na área de gestão ambiental, pois a grande maioria das empresas demonstra interesse na participação dos mesmos.

Entre tais programas, pode-se, por exemplo, trabalhar a questão da reutilização e reciclagem dos $R C D$, ainda pouco trabalhado nas construções brasileiras. É interessante frisar que não se pode pensar em construções limpas ou Desenvolvimento Sustentável na área da construção civil, sem antes se refletir sobre a questão da gestão ambiental.

Em termos de destinação final dos RCD, observa-se que é necessária uma melhor gestão por parte dos construtores, notadamente no que se diz respeito a diminuir as perdas no processo produtivo e na reutilização dos materiais reaproveitáveis, com vistas a diminuir a quantidade de resíduo descartável produzido, bem como o envio dos RCD aos locais apropriados. Em termos de reformas e demolições, faz-se necessário a absorção da prática do reuso e da reciclagem dos $R C D$, o que, desta forma, reduziria o volume dos materiais descartados.

Ainda com relação à destinação final dos RCD, necessário se faz que o Poder Público, através dos órgãos competentes, possa exercer uma efetiva fiscalização com vistas a coibir que as empresas joguem seus excedentes em locais impróprios, o que acarreta sérios problemas ao meio ambiente. Como também, fiscalizar e exigir o licenciamento ambiental das empresas, incluindo a apresentação do PGRCD (Programa de Gerenciamento dos Resíduos da Construção e Demolição), além de incentivar a implantação de usinas de beneficiamento de RCD no município.

Para efetivação dos pressupostos do desenvolvimento sustentável e de uma construção mais limpa, necessário se faz por parte dos atores envolvidos, notadamente aqueles ligados diretamente à produção (construção civil) e os gestores públicos a adoção de políticas e ações que tenham por objetivo atenuar e minimizar os impactos ambientais oriundos do processo produtivo, tais como, ações integradas de "educação ambiental", de forma contínua e sistematizada, a serem trabalhadas com a população local, com o intuito de romper a cultura da gestão corretiva e implantar uma gestão democrática, participativa e preventiva.

\section{REFERÊNCIAS BIBLIOGRÁFICAS}

1. ADALGIZA, Ana. Quadro de Acompanhamento de Lançamentos Imobiliários. [mensagem pessoal] Mensagem recebida por: <Alcimar Santos>, em: 24 mar. 2009. 
2. AGOPYAN, V.F.; JOHN, V.M. Reciclagem de Resíduos da Construção. Artigo. Escola Politécnica da USP, Departamento de Construção Civil, São Paulo, 2000.

3. BRITO FILHO, J.A. Cidade Versus Entulho. In: Seminário de Desenvolvimento Sustentável e a Reciclagem na Construção Civil, 2., São Paulo, 1999. Anais. São Paulo, Comitê Técnico CT206 Meio Ambiente (IBRACON), 1999. p. 56-67.

4. COOPHAB - COOPERATIVA HABITACIONAL DOS SERVIDORES E TRABALHADORES SINDICALIZADOS DO RIO GRANDE DO NORTE. Disponível em http://www.coophab.com.br. Acesso em 22.01.13.

5. CONAMA - CONSELHO NACIONAL DE MEIO AMBIENTE. Resolução no. 307, de 05 de julho de 2002. Disponível em: http://www.mma.gov.br/port/conama/res/res02/res30702.htm. Acesso em 27.04.13.

6. COSTA, L.F. Estratégia Ambiental na Indústria da Construção Civil: Um Estudo sobre Fatores Direcionadores de Percepção Ambiental de Construtores de Imóveis. 2005. Dissertação (Mestrado), Engenharia de Produção, UFRN, Natal, 73 p.

7. COSTA, N.A.A. A Reciclagem do RCD: Uma Aplicação da Análise Multivariada. 2003. Tese (Doutorado), Programa de Pós-Graduação em Engenharia de Produção, UFSC, 188 p.

8. DEGANI, C.M. Sistemas de Gestão Ambiental em Empresas Construtoras de Edifícios. 2003. 223 f. Dissertação (Mestrado). Escola Politécnica da USP, Departamento de Construção Civil, Universidade de São Paulo, São Paulo, 2003.

9. FILHO, A.F.S. Gestão dos Resíduos Sólidos das Construções Prediais na Cidade do Natal-RN. 2005. Dissertação (Mestrado), Programa de Engenharia de Produção, UFRN, 118p.

10. GIL, António Carlos. Métodos e técnicas de pesquisa social. 5 ed. São Paulo: Atlas, 1999.

11. IBGE - INSTITUTO BRASILEIRO DE GEOGRAFIA E ESTATÍSTICA. Disponível em http://www.ibge.gov.br/cidadesat/topwindow.htm. Acesso em 20.08.13.

12. JOHN, V.M.J. Reciclagem de resíduos na construção civil: contribuição à metodologia de pesquisa e desenvolvimento. Tese (livre docência). Escola Politécnica da Universidade de São Paulo, São Paulo, 2000.

13. MONTEIRO, J.H.P. et al. Manual de Gerenciamento Integrado de resíduos Sólidos. Rio de Janeiro: IBAM, 2001.

14. PINTO, T. P. Gestão dos resíduos de construção e demolição em áreas urbanas - da ineficácia a um modelo de gestão sustentável. In: Reciclagem de Entulho para a produção. Salvador: Editora da UFBA, 2001.

15. PINTO, T. P. Metodologia para a gestão diferenciada de resíduos sólidos da construção urbana. Tese (doutorado) - Escola Politécnica, USP, São Paulo, 1999.

16. PINTO, T. P. Perda de Materiais em Processos Construtivos Tradicionais. Departamento de Engenharia Civil da UFSCAR (texto datilografado), 1989, 33 p.

17. PINTO, T.P. A Nova Legislação para Resíduos Sólidos da Construção. Revista TECNE, edição 82, PINI, São Paulo, jan. 2004, p. 62-63.

18. SCHNEIDER, D.M. Deposições Irregulares de Resíduos da Construção Civil na Cidade de São Paulo, 2003, Dissertação (Mestrado), Programa de Pós-Graduação em Saúde Pública, Universidade de São Paulo, 131 p. 
19. SINDUSCON-SP. Apresentações dos palestrantes no seminário "Gestão dos resíduos da construção: a legislação na cidade de São Paulo”. 03 de maio de 2005: São Paulo, 2005.

20. SOUZA et al. Desperdício de Materiais nos Canteiros de Obras: a Quebra do Mito. In: Simpósio Nacional: Desperdício de Materiais nos Canteiros de Obras: A Quebra do Mito. São Paulo, 1999. Anais. São Paulo (PCC/EPUSP), 1999. 48 p.

21. TAVARES, L. P. M.. Levantamento e análise da deposição e destinação dos resíduos da construção civil em Ituiutaba, MG. 2007. 160 f. Dissertação (Mestrado) - Curso de Programa de Pós-graduação em Engenharia Civil, Faculdade de Engenharia Civil, Universidade Federal de Uberlândia, Uberlândia, 2007.

22. VERgARA, S.C. Projetos e Relatórios de Pesquisa em Administração. São Paulo: Atlas, 1998.

23. ZORDAN, S.E. A Utilização do Entulho como Agregado na Confecção do Concreto. Dissertação (Mestrado), Faculdade de Engenharia Civil, UNICAMP, Campinas. 140 p., 1997. 